\title{
Construction Scale Prediction of CHENCHOU Logistics Center in Hunan Province*
}

\author{
Shijun Yuan \\ Hunan Vocational College of Modern Logistics \\ Changsha, China 410131
}

\author{
Jianhua Chen** \\ Hunan Vocational College of Modern Logistics \\ Changsha, China 410131 \\ **Corresponding Author
}

\begin{abstract}
Based on the full analysis of industrial, commercial, agricultural and other logistics demands and logistics supply in the radiation area of Hunan CHENCHOU Logistics Center project, this paper uses forecasting model to predict the construction scale of logistics center, and provides reference for project construction.
\end{abstract}

Keywords-logistics center; construction scale; prediction

\section{INTRODUCTION}

Hunan CHENCHOU has good local transportation advantages, rich material resources, and has good basic conditions for logistics development. However, the local regional logistics service supply capacity is relatively backward. Hunan CHENCHOU Logistics Company is planning to build a logistics center in CHENCHOU, which needs to predict the construction scale of the logistics center.

\section{ANALYSIS OF LOGISTICS DEMAND IN THE ProJECT RADIATION AREA}

\section{A. Strong Demand for Industrial Logistics in the Project Radiation Area}

The project radiation area has a good industrial base and complete categories, and is an important industrial base in the province. Among the industrial categories that have been built, there are six major industries, such as nonferrous metals, energy, electronic information, building materials and medicines, food chemicals, and machinery. The annual volume of goods in and out is huge. In recent years, the industrial economy has developed rapidly with an annual increase of $20 \%$, and the total industrial economy has been rising. The mineral resources in the radiant area are known for their variety and huge reserves. There are 110 kinds of minerals that have been discovered, and 7 categories of 70 kinds have been proven reserves.

We have investigated the key manufacturing enterprises in the project radiation area, many enterprises believe that logistics has become the key to the expansion and strengthening of companies in industrial parks. The demand for quality logistics services is becoming stronger and stronger, and the demand for logistics centers is becoming more and

*Phased Achievements of Scientific Research Project (15C0962) of Hunan Provincial Department of Education. more urgent.

Through the investigation and research on the logistics demand of manufacturing enterprises in the radiation area, it can be concluded from the statistical data analysis that most of the manufacturing enterprises' logistics forms are mainly using the form of Third party logistics outsourcing weather raw material purchase or the products transportation, self-owned logistics has a low proportion. The form of third-party logistics outsourcing is mainly considered by manufacturers in terms of cost saving and core production of centralized capital development. Therefore, this provides favorable conditions for third-party logistics company to open up the market. In terms of the selection and evaluation of logistics providers, different companies have different requirements and levels for the service projects of logistics companies, but the overall situation is relatively good, and the logistics companies that cooperate with their respective enterprises have solved the problems appeared in the specific operation process that suits the company.

However, due to the fact that there is still a large part of the manufacturing enterprises in the radiation area haven't yet reached a certain level of the understanding of logistics. Relatively speaking, the level is low, they did not consider the future development of the company from overall aspect, so they waste a lot of the logistics resources and the logistics cost is high, this will also make the product price high, and finally lead to market competitiveness is difficult to improve, and the product market share is reduced.

Improve the company's awareness of logistics and reduce logistics costs is an important way for third-party logistics companies to expand their markets. In addition, for logistics companies, if the project service can be customized for the service requirements of different enterprises, use large-scale customized logistics model to meet the service level requirements of different enterprises, the logistics cost and service quality can be optimized, eventually it will be able to seize the market. As regional manufacturing companies, their business is still mainly within the province, so local third-party logistics companies still have considerable advantages. 


\section{B. The Logistics Demand for Commercial Enterprises Is Growing}

We conducted research on the logistics service demands of major customers such as general agents and general distribution in the professional market of the project radiation area. In terms of whether enterprise logistics adopts self-care or outsourcing, each enterprise gives a logistics responsibility method suitable for the enterprise itself. Among them, $38 \%$ of enterprises adopt logistics self-care, they have their own fleets and warehouses, and very few even have modern threedimensional warehouses. And 54\% of enterprises are satisfied with self-care logistics. The reasons for satisfaction are mainly reflected in low operating costs, fast operation speed, timely and accurate logistics information, fluctuation of demand can be meet, low loss rate and wide network coverage. On the other hand, enterprises provide logistics to suppliers and thirdparty logistics companies also propose corresponding service contents: logistics information management, simple warehousing, trunk shipping, urban distribution, $73 \%$ of enterprises are satisfied with this. In selecting new logistics agents, $53 \%$ of enterprises emphasize economics, $33 \%$ of enterprises emphasize the importance of operation quality.

Through the survey of the logistics in various key commercial enterprises, analyze from the survey data that: the development of local logistics industry is still in its initial stage, in some small enterprises, the overall logistics level is not high, the structure is not perfect, the logistics equipment is not complete, the total logistics costs are high, some companies even have no logistics concept. The employees are not clear about the logistics process, lack of senior talents in logistics. In warehouse management, there is no advanced management system and advanced information system. In some large enterprises, they are relatively large in scale, so their logistics facilities are relatively complete, so their logistics development is relatively fast. In general, logistics has great room for development in the field of commercial logistics services.

The surveyed enterprises have put forward their own opinions and suggestions on accelerating the development of modern logistics. They mainly include simplifying the customs clearance and inspection time and improving the logistics speed; integrating, collecting logistics resources, and vigorously cultivating the logistics market; improving the understanding of logistics through propagate; planning and guiding to strengthen infrastructure construction; guide and encourage industrial and commercial enterprises to carry out logistics reform; implement brand strategy and cultivate leading enterprises in modern logistics.

\section{The Logistics Demand of Agricultural Products and Processing Industry Is Highlighted}

The agricultural resources of the project radiation area are quite rich, agriculture plays an important role in its overall economy. The product processing chain based on agricultural products is an important future direction. In recent years, the agricultural product processing industry has developed rapidly and the scale of agricultural product logistics has expanded rapidly.
There are nearly 100 leading agricultural product enterprises in the city. The city's agricultural products form eight types include food (mainly rice), livestock and poultry (sow pigs, beef cattle, ducks, etc.), aquatic products, fruits and flue-cured tobacco.

Modern agriculture is accelerating its development. There are more than 150 leading enterprises above the city level in the city, achieving a total output value of 7 billion yuan, with an increase rate of $45 \%$; driving the total output value of the base 4 billion yuan, the increase rate is $30 \%$. 10 provinciallevel demonstration sites for new farmers' professional cooperatives were established. There are 1000 professional cooperative organizations for farmers and 200,000 members of cooperative organizations.

\section{THE ANALYSIS OF LOGISTICS SUPPLY IN PROJECT RADIATION AREA}

\section{A. Cargo Vehicle Holing Capacity}

At present, the city has a total of more than 400,000 vehicles of various types, including more than 60,000 passenger vehicles, 50,000 trucks, and more than 300,000 motor vehicle drivers.

\section{B. Level of Information Construction}

In terms of information communication, digital communication, microwave communication, satellite communication and optical cable transmission systems cover the whole city, basically achieving rural communication coverage rate of $100 \%$, digital TV translation, telephone penetration rate is more than $70 \%, 90 \%$ of government departments are networking, $80 \%$ of government functions are online, and enterprises above designated size basically implement computer-aided design, integrated manufacturing, and digital management.

\section{Development Status of Small and Medium-sized Logistics Enterprises}

Through the investigation of small and medium-sized logistics enterprises in the project radiation area, a total of 89 valid questionnaires were collected. By visiting these logistics enterprises, we find that:

- At present, the overall development of logistics in the project radiation area is small scale, the development form and level are far from enough. On the hardware side, the number of vehicle warehouse is limited. Most of the enterprises temporarily transfer vehicles from the society when the business occurs, which can save part of the cost, but cannot effectively ensure the quantity and accuracy and timely of the vehicles, and there are monitoring inconveniences in the transportation process. At the same time, the small and medium-sized logistics enterprises in the project radiation area basically have no warehouses, more common is they use rented facades for both warehouses and offices, and even some of them as residences too, the development is not standardized. 
- Currently the logistics development pattern of the small and medium-sized enterprises of project radiation area is still in initial stage, and the services provided by enterprises have limitations in depth and breadth, the value-added function through logistics has not been fully exerted.

- The business coverage of small and medium-sized logistics enterprises in the project radiation area is basically wide. Through investigations, it is known that besides some Northwest provinces, most logistics enterprises have conditions or have had logistics transactions. Very few small logistics enterprises only undertake the transportation within the city. However, in the investigation, it was found that the project radiation area has great potential for logistics exchanges with the provinces in Hunan Province and surrounding provinces. At present, there has been small development, but the logistics network still has insufficient soundness.

- Small and medium-sized logistics enterprises in the project radiation area are booming. Most of the enterprises are forward-looking and can effectively plan the development prospects of the enterprises.
There are also a few enterprises that lack strategic vision and are comfortable with their current situation.

- Through investigations, it is found that the construction of new logistics centers in the project radiation area is very promising. Most enterprises have expressed their approval or interest, their expectations focus on good service attitude, high-level hardware facilities, strong government support, and benign Competitive environment, convenient traffic conditions, etc.

\section{DEMAND PREDICTION}

In the coming period, the social economy of the project radiation area will be in a period of rapid development, and its logistics demand will be greatly increased.

According to historical freight volume data, conduct data fitting and build prediction model can predict the development trend of future freight volume. Time series analysis is made for the comprehensive freight volume data of the project radiation area in 2009-2017. "Table I"

TABle I. The Statistics SheEt For the Comprehensive Freight Volume of the Project Radiation ARea in ReCENT Years

\begin{tabular}{|c|c|c|c|c|c|r|r|r|r|}
\hline Year & $\mathbf{2 0 0 9}$ & $\mathbf{2 0 1 0}$ & $\mathbf{2 0 1 1}$ & $\mathbf{2 0 1 2}$ & $\mathbf{2 0 1 3}$ & $\mathbf{2 0 1 4}$ & $\mathbf{2 0 1 5}$ & $\mathbf{2 0 1 6}$ & $\mathbf{2 0 1 7}$ \\
\hline Total & 8162 & 8565 & 8968 & 9371 & 9774 & 10177 & 10580 & 11230 & 11869 \\
\hline
\end{tabular}

Calculated by the logistics demand model, the predicted results are "Table II":

TABLE II. THE PREDICTED VALUE FOR THE COMPREHENSIVE FREIGHT VOLUME OF THE PROJECT RADIATION AREA

\begin{tabular}{|c|r|r|}
\hline Predicted Year & $\mathbf{2 0 2 0}$ & $\mathbf{2 0 2 5}$ \\
\hline Comprehensive freight volume & 13922 & 16938 \\
\hline
\end{tabular}

${ }^{\text {a. }}$ Unit: 10 thousand tons

There are many factors affecting the planning construction scale of the logistics center. Here we use the total amount of logistics in the city which has been used more often to explore the overall construction scale of the city logistics center. In the regional logistics planning, if the number of working days per year is $365 \mathrm{~d}$, the total construction scale of the logistics center is:

\section{$\mathrm{S}=\mathrm{LI} 1 \mathrm{I} 2 \mathrm{a} / 365$}

In the formula: $S$ is the total construction area of the logistics center (m2); $\mathrm{L}$ is the total social logistics volume $(\mathrm{t})$ for the predicted planning target year; I1 is the proportion of the third-party logistics (3P L) market in the planning target year to the whole society logistics market ; I 2 is the proportion of the amount of work carried out through the logistics center to the whole 3P L logistics operations in the planned target year; $\mathrm{a}$ is the parameter of land production capacity per unit $\mathrm{m} 2 / \mathrm{t})$.

According to the status quo and trend of the development of logistics in the project radiation area and the radiation ability to the surrounding area, the total construction scale of the Hunan HG Logistics Center (2020) is:

\section{$\mathrm{S}=\mathrm{L}$ I1I2I3a $/ 365$}

In the formula: $S$ is the total construction area of the logistics center $(10,000$ square meters $)$; $\mathrm{L}$ is the predicted total social logistics volume (10,000 tons) predicted for 2015. Considering that the main transportation mode of the logistics center is road transportation, so the total social logistics volume of the logistics center choose road freight volume, which was 139.22 million tons; I1 is the proportion of the third-party logistics (3PL) market in the planning target year to the total society logistics market, considering the regional economic aggregate and market maturity, choose the value below $20 \%$, which is $15 \%$; I 2 is the proportion of the amount of work carried out through the logistics center to the whole 3P $\mathrm{L}$ logistics operations in the planned target year is $30 \%$; I3 is the proportion of third-party traffic attracted by Hunan HG Logistics Center to the total amount is $20 \%$; a is the parameter of land production capacity per unit, the local economic aggregate is not large, and the radiation to the surrounding area is not too strong, so a takes a small value of $35 \mathrm{~m} 2 / \mathrm{t}$.

$$
\mathrm{S}=13922 * 15 \% * 30 \% * 20 \% * 35 / 365
$$

\section{$\mathrm{S}=120.1$ Thousand square meters}

\section{CONCLUSION}

The prediction of the construction plan of the logistics center should be fully analyzed in the industrial logistics demand of the project radiation area, the logistics demand of 
the trade circulation industry, the logistics demand of agricultural products, etc., and based on the evaluation of the current logistics supply capacity of the project radiation area, the prediction model can be used for prediction and provide reference for the determination of the project construction scale.

\section{REFERENCES}

[1] Tang Xiaohong, Yan Yonggang. Research on Land Use Scale of Logistics Park Based on Freight Volume. Prediction[J]. Logistics Technology. 2016(05).

[2] Li Yumin, Li Xuhong, Mao Haijun, Tao Jinghui. Method for determining the scale of logistics park planning and construction[J]. Journal of Traffic and Transportation Engineering. 2004(02).

[3] Yao Zhigang, Liu Zhikai, Zhang Sansheng. Discussion on the Method of Determ ining the Scale of Logistics Park[J]. Comprehensive Transportation. 2003(03). 